\title{
Intellectual giftedness for leadership: how robust is the crime reducing effect of intellectual class?
}

\begin{abstract}
ABSTRCT
This paper aims to reassess Burhan et al.'s (2014) findings on the crime-reducing impact of intelligence at a cross-country level. The cognitive level of the intellectual group, defined as those with IQ at the 95th percentile of the normal distribution, was found to have a stronger impact in terms of crime rate reduction than the average level (50th percentile). This was demonstrated using ordinary least squares (OLS). The cognitive level of the non-intellectual class ( 5 th percentile IQ) was found to be least important in reducing crime. However, in their study, many independent variables were stated as not significantly related to the crime rates, which contradicts other literature. The question arises whether the presence of serious outliers in the samples causes the inconsistent findings. In this study, we analyzed the impact of IQ classes on the rates of eight different types of crime, namely homicide, rape, kidnapping, robbery, assault, burglary, property crimes, and vehicle theft. In addition to OLS we use Tukey's Bisquare robust M-estimator, which mitigates the effects of outliers in the samples. We conclude that those from the intellectual class play a more significant role than people of average ability and those of the non-intellectual class in reducing crime rates. Thus, educational policies for the gifted are recommended in order for them to become active participants in the future transformation of their societies, enhancing the functionality and quality of institutions and thereby reducing crimes.
\end{abstract}

Keyword: Intelligence; Intellectuals; Non-intellectuals; Crime

rates; Leadership. 